\title{
Do pulmonary function tests improve risk stratification before cardiothoracic surgery?
}

\author{
Alexander Ivanov, MD, ${ }^{a}$ James Yossef, MD, ${ }^{a}$ Jordan Tailon, MD, ${ }^{a}$ Berhane M. Worku, MD, \\ Iosif Gulkarov, MD, ${ }^{\mathrm{b}}$ Anthony J. Tortolani, MD, ${ }^{\mathrm{b}}$ Terrence J. Sacchi, MD, ${ }^{\mathrm{a}}$ William M. Briggs, PhD, \\ Sorin J. Brener, MD, ${ }^{a}$ Jeremy A. Weingarten, MD, ${ }^{a}$ and John F. Heitner, MD ${ }^{\mathrm{a}}$
}

\begin{abstract}
Objective: To assess the added value of pulmonary function tests (PFTs) and different classifications of chronic obstructive pulmonary disease (COPD) to the Society of Thoracic Surgeons (STS) risk model using a clinical definition of lung disease for predicting outcomes after cardiothoracic (CT) surgery.
\end{abstract}

Methods: We evaluated consecutive patients who underwent nonemergency cardiac surgery and underwent PFTs before CT surgery. We used the STS risk model 2.73 to estimate the postoperative risk for respiratory failure (RF; defined as the need for mechanical ventilation for $\geq 72$ hours, or reintubation), prolonged postoperative stay (PPLS; defined as $>14$ days), and 30-day all-cause mortality. We plotted the receiver operating characteristics curve for STS score for each adverse event, and compared the resulting area under the curve (AUC) with the AUC after adding PFT parameters and COPD classifications.

Results: Of the 1412 patients with a calculated STS score, 751 underwent PFTs. The AUC of the STS score was 0.65 (95\% confidence interval [CI], 0.55-0.74) for RF, 0.67 (95\% CI, 0.6-0.74) for prolonged postoperative length of stay (PPLS), and 0.74 (95\% CI, 0.6-0.87) for death. None of the PFT parameters or COPD classifications added to the predictive ability of STS for RF, PPLS, or 30-day mortality.

Conclusions: Adding individual PFT parameters or different COPD classifications to STS score calculated using clinically based classification of lung disease did not improve model discrimination. Thus, routine preoperative PFTS may have limited clinical utility in patients undergoing CT surgery when the STS score is readily available. (J Thorac Cardiovasc Surg 2016;151:1183-9)

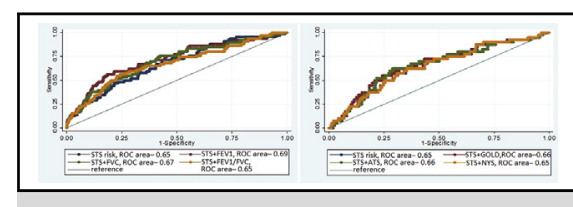

Receiver operating characteristic analysis for respiratory failure in patients with PFTs.

\section{Central Message}

Routine preoperative pulmonary function tests may have limited utility in patients undergoing cardiothoracic surgery when the Society of Thoracic Surgeons score is available.

\section{Perspective}

In our practice, pulmonary function test (PFTs) are usually performed in patients with a higher burden of comorbidity scheduled for more complex cardiothoracic surgery. The Society of Thoracic Surgeons (STS) score based on clinical definitions of lung disease afforded modest discriminatory ability for 3 studied outcomes. Adding individual PFT parameters or any of the chronic obstructive lung disease classifications did not improve the discriminatory ability of STS score alone.

See Editorial Commentary page 1189.

See Editorial page 918.
Respiratory failure (RF) is a frequent complication after cardiothoracic (CT) surgery, ranging in frequency from $2 \%$ to $22 \%$, depending on the population studied and the definitions used. ${ }^{1-6}$ Numerous studies have identified RF as associated with increases in hospital length of stay, morbidity, and postoperative mortality, as well as greater resource utilization and costs. , $^{2,11}$

\footnotetext{
From the ${ }^{\mathrm{a}}$ Department of Medicine and ${ }^{\mathrm{b}}$ Division of Cardiothoracic Surgery, New York Methodist Hospital, Brooklyn, NY; and ${ }^{\mathrm{c}}$ Department of Statistical Sciences, Cornell University, Ithaca, NY.

Received for publication July 20, 2015; revisions received Oct 15, 2015; accepted for publication Oct 26, 2015; available ahead of print Dec 15, 2015.

Address for reprints: John F. Heitner, MD, New York Methodist Hospital, 506 6th St, Brooklyn, NY 11215 (E-mail: jfh9003@nyp.org).

$0022-5223 / \$ 36.00$

Copyright (c) 2016 by The American Association for Thoracic Surgery

http://dx.doi.org/10.1016/j.jtcvs.2015.10.102
}

The most recent data from retrospective studies evaluating different predictors of RF after CT surgery have questioned the predictive value of chronic obstructive pulmonary disease (COPD) classification before surgery. However, individual pulmonary function test (PFT) parameters, such as forced expiratory volume in 1 second (FEV1), have been shown to be independent predictors of adverse outcomes, including postoperative mortality and RF. ${ }^{9,10,12}$ In addition, forced vital capacity (FVC) has

Scanning this QR code will take you to supplemental figures and tables for this article.

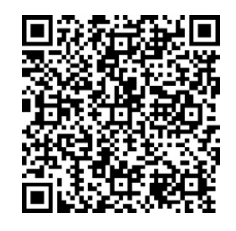




Abbreviations and Acronyms
$\begin{array}{ll}\text { ATS } & =\text { American Thoracic Society } \\ \text { AUC } & =\text { area under the curve } \\ \text { CABG } & =\text { coronary artery bypass grafting } \\ \text { COPD } & =\text { chronic obstructive pulmonary disease } \\ \text { CT } & =\text { cardiothoracic } \\ \text { CVA } & =\text { cerebrovascular accident } \\ \text { FEV1 } & =\text { forced expiratory volume in } 1 \text { second } \\ \text { FVC } & =\text { forced vital capacity } \\ \text { NYMH } & =\text { New York Methodist Hospital } \\ \text { NYSDOH } & =\text { New York State Department of Health } \\ \text { PFT } & =\text { pulmonary function test } \\ \text { PPLS } & =\text { prolonged postoperative length of stay } \\ \text { RF } & =\text { respiratory failure } \\ \text { ROC } & =\text { receiver operating characteristic } \\ \text { STS } & =\text { Society of Thoracic Surgeons }\end{array}$

been identified as a powerful independent predictor of mortality in the general population. ${ }^{13}$

The Society of Thoracic Surgeons (STS) risk model is a well-recognized and widely used tool for predicting adverse outcomes after CT surgery. It was developed and validated based on a national database comprising nearly 1 million patients. The data were used to create a statistical model predicting RF and 8 other postoperative outcomes. ${ }^{14-17}$ Based on definitions used in the STS risk model, the presence and severity of chronic lung disease (CLD) may be defined by either clinical criteria or spirometry testing; however, a major underestimation of the prevalence and severity of CLD was reported when only the STS clinical criteria were used. ${ }^{18}$ Moreover, the same study noted a significant underestimation of the incidence of adverse outcomes when only spirometry was included in the risk models.

The aim of the present study was to assess the added value of PFTs and classifications of COPD based on PFT results to the STS risk score derived from clinical data alone for predicting RF, prolonged postoperative length of stay (PPLS), and 30-day mortality in patients undergoing CT surgery.

\section{METHODS}

The study was approved by the Institutional Review Board of New York Methodist Hospital (NYMH), which waived the requirement for individual consent.

\section{Patient Population}

The study cohort comprised a total of 1685 patients who underwent index cardiac surgery at NYMH between April 2004 and January 2014. We excluded patients classified as unstable (ie, requiring pharmacologic and or mechanical support to maintain adequate blood pressure), patients who had undergone an emergency procedure (ie, earlier than planned surgery owing to ongoing, refractory, unrelenting cardiac compromise with or without hemodynamic instability) or a procedure not supported by the STS calculator, and patients who were lost to follow-up within 30 days after CT surgery (Figure 1).

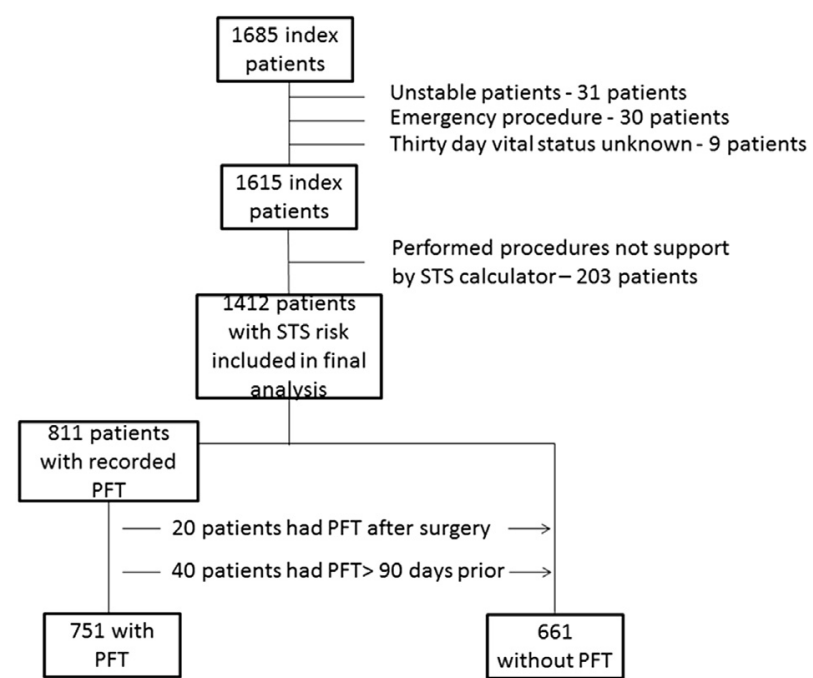

FIGURE 1. Patient flowchart. STS, Society of Thoracic Surgeons; $P F T$, pulmonary function test.

\section{Data Acquisition}

PFT reports were obtained from the NYMH Pulmonary Physiology Laboratory database. Demographic, clinical, procedural, and outcome data were obtained from patient charts. Data were originally entered prospectively and submitted quarterly to the NYSDOH Division of Quality and Patient Safety Cardiac Services program using NYSDOH Form 2254a, in accordance with state requirements.

\section{STS Risk Calculation}

STS risk was calculated retrospectively using the online STS calculator version 2.73 (http://riskcalc.sts.org), accessed between May 1 and August 1, 2014. Because of software limitations, STS risk was not calculated for patients undergoing double-valve interventions or 3 simultaneous surgical procedures. We calculated STS risk using data on the type of surgical procedure performed; patient age, sex, race, ethnicity, height, and weight; cardiac presentation; symptoms at the time of admission and time of surgery; left ventricular ejection fraction; history of recent heart failure, previous myocardial infarction, cardiac arrhythmias, CLD, cerebrovascular disease, peripheral artery disease, diabetes, hypertension, immunocompromised state, endocarditis, creatinine level, and renal dialysis; presence and severity of coronary artery disease, including involvement of the left main coronary artery; status of the procedure; and presence and extent of valvular disease. CLD was evaluated based solely on clinical parameters without PFT data (Table 1).

STS calculates the risk for 9 postoperative parameters, and here we report data for 3 of these: (1) operative mortality (death during the same hospitalization as surgery, regardless of timing, or within 30 days of surgery regardless of venue); (2) prolonged ventilation ( $>24$ hours); and (3) prolonged postoperative hospital stay ( $>14$ days after the date of surgery).

\section{PFTs}

The decision to perform PFTs was left to the discretion of the treating physician. Of the 751 patients who underwent PFTs, 652 had bedside spirometry testing and 99 had formal laboratory PFTs. PFTs were performed with the SpiroPro spirometer and Vmax Encore PFT System (CareFusion, San Diego, Calif). Outpatients were instructed to refrain from smoking and using bronchodilators for at least 4 hours before testing. The FEV1 and FVC values were determined by taking the best of 3 trials. The severity of airway obstruction was categorized according to the Global 
TABLE 1. Different definitions of COPD used in the study

\begin{tabular}{|c|c|c|}
\hline & FEV1/FVC\% & FEV1\% \\
\hline \multicolumn{3}{|c|}{ GOLD COPD classification } \\
\hline No & $\geq 70$ & \\
\hline Mild & $<70$ & $\geq 80$ \\
\hline Moderate & $<70$ & $50 \leq \mathrm{FEV} 1<80$ \\
\hline Severe & $<70$ & $<50$ \\
\hline \multicolumn{3}{|l|}{ ATS COPD classification } \\
\hline No & $\geq 70$ & \\
\hline Mild & $<70$ & $\geq 80$ \\
\hline Moderate & $<70$ & $60 \leq$ FEV $1<70$ \\
\hline Moderately severe & $<70$ & $50 \leq$ FEV $1<60$ \\
\hline Severe & $<70$ & $<50$ \\
\hline \multicolumn{3}{|c|}{ NYS COPD criteria } \\
\hline $\begin{array}{l}\text { Chronic bronchodilator } \\
\text { therapy* }\end{array}$ & FEV1* & $\begin{array}{l}\text { Blood gas } \\
\text { parameters* }\end{array}$ \\
\hline More than 3 months & $\begin{array}{c}<75 \% \text { of the predicted } \\
\text { value or }<1.25 \mathrm{~L}\end{array}$ & $\begin{array}{l}\text { Room air } \mathrm{O}_{2} \\
\quad \text { tension }<60 \text { or } \\
\mathrm{CO}_{2} \text { tension }>50\end{array}$ \\
\hline
\end{tabular}

\begin{tabular}{|c|c|c|c|}
\hline \multicolumn{4}{|c|}{ STS chronic lung disease } \\
\hline Mild & Moderate & Severe & Unknown \\
\hline $\begin{array}{l}\text { Chronic inhaled } \\
\text { or oral } \\
\text { bronchodilator } \\
\text { therapy }\end{array}$ & $\begin{array}{l}\text { Chronic steroid } \\
\text { therapy aimed } \\
\text { at lung disease }\end{array}$ & $\begin{array}{l}\text { Room air } \\
\mathrm{CO}_{2} \text { tension } \\
>50\end{array}$ & $\begin{array}{l}\text { History of chronic } \\
\text { inhalation reactive } \\
\text { disease (asbestosis, } \\
\text { mesothelioma, } \\
\text { black lung disease, } \\
\text { or pneumoconiosis) }\end{array}$ \\
\hline
\end{tabular}

FEV1, Forced expiratory volume in 1 second; $F V C$, forced vital capacity; GOLD, Global Strategy for the Diagnosis, Management, and Prevention of COPD; $C O P D$, chronic obstructive pulmonary disease; ATS, American Thoracic Society 2001 classification; NYS COPD, New York State criteria for chronic obstructive pulmonary disease (New York State Department of Health Division of Quality and Patient Safety Cardiac Services program using Department of Health Form 2254a 2011); STS, Society of Thoracic Surgeons. *The presence of any of the 3 criteria is sufficient to diagnose COPD.

Strategy for the Diagnosis, Management, and Prevention of COPD ${ }^{19}$; American Thoracic Society (ATS) guidelines ${ }^{20}$; and New York State Department of Health (NYSDOH) 2011 instructions (Table 1). Observed FEV1 and FVC data are reported as raw value and percentage of predicted value for each patient. COPD was diagnosed in cases of an FEV1/FVC ratio $<70 \%$.

\section{Outcomes}

The outcomes of interest were RF, defined as need for mechanical ventilation for 72 hours or longer, or reintubation and mechanical ventilation after postoperative extubation; PPLS, defined as more than 14 days between the day of surgery and hospital discharge day; and 30-day all-cause mortality, defined as death within 30 days after CT surgery.

\section{Data Analysis}

Continuous data are presented as mean and standard deviation (SD), and categorical data are presented as frequency. Variables with a non-Gaussian distribution are presented as median and interquartile range (IQR). Continuous variables were compared using the Student $t$ test (for 2 groups) or analysis of variance (for 3 or more groups). Continuous variables with a non-Gaussian distribution were compared using the Mann-Whitney $U$ test. The $\chi^{2}$ test was used for categorical variables with a normal distribution.
Logistic regression analysis was performed on STS risk and sequential models (STS+FEV1; STS +FVC, etc) and various COPD classifications.

Based on the results of logistic regressions for corresponding models, receiver operating characteristic analysis was performed to quantify the discriminatory ability for STS- predicted risk for each outcome of interest (ie, area under the curve [AUC]). The STS-alone AUC served as a reference. A $P$ value of $<.05$ was considered statistically significant. All calculations were performed using $\mathrm{R}$ version 3.1.2 (R Foundation for Statistical Computing, Vienna, Austria) and Stata 12.1 (StataCorp, College Station, Tex).

\section{RESULTS \\ Baseline Characteristics}

The baseline characteristics of 1412 cardiac surgery patients with available STS risk scores, including 751 $(53 \%)$ with PFTs and $661(47 \%)$ without PFTs performed before CT surgery, are outlined in Table 2. In general, compared with patients without PFTs, those with PFTs were older and had higher rate of comorbidities and complex CT surgery. They also had elevated STS risk for prolonged ventilation $(12.4 \%$ vs $10.3 \% ; P<.001)$, PPLS $(8.9 \%$ vs $7.2 \% ; P<.002)$, and 30 -day mortality $(2.7 \%$ vs $2.2 \% ; P<.003)$.

\section{Clinical Outcomes}

Sixty-four patients $(4.5 \%)$ developed postoperative RF. There was no statistically significant difference in the RF rate between patients with PFTs and those without PFTs $(5.3 \%$ vs $3.6 \% ; P=.13)$. Ninety-seven patients $(6.9 \%)$ had a PPLS, and there was a significantly higher rate of PPLS in the patients with PFTs $(8.8 \%$ vs $4.7 \%$; $P<.002)$. Twenty-eight $(2 \%)$ patients died within 30 days after surgery, with no significant difference in 30-day mortality between patients with and without PFTs $(1.9 \%$ vs $2.1 \% ; P=.73)$. Please see Table E1 for results of multivariate logistic regressions for studied outcome.

The discriminatory ability of the STS score for each of these 3 postoperative complications in patients with PFT is shown in Tables 3 and 4 and Figure 2. The AUCs for these STS risk estimations in the entire cohort of 1412 patients were 0.67 (95\% confidence interval [CI], 0.6-0.73) for RF, 0.71 (95\% CI, 0.65-0.76) for PPLS, and 0.76 (95\% CI, 0.67-0.84) for 30-day mortality. There was no difference in the c-statistic of STS risk for predicting analyzed outcomes between patients with and without PFTs $(P>.14$ for all; Figures E1-E3). These tables also show the change in AUC when PFT parameters and COPD classifications were added individually to the STS score. In general, STS score alone had only modest discriminatory ability for each complication (AUC, 0.64-0.74). None of the PFT parameters or COPD classifications significantly improved the STS score performance (see Table E2 and Table E3 for observed/expected event ratios). See Figure E4 for ROC comparing normalized and non-normalized PFT parameters. 
TABLE 2. Baseline characteristics

\begin{tabular}{|c|c|c|c|c|}
\hline Parameter & All patients & No PFTs & PFTs & $P$ value \\
\hline Patients, n (\%) & $1412(100)$ & $661(47)$ & $751(53)$ & \\
\hline \multicolumn{5}{|l|}{ Demographics } \\
\hline Age, year, mean \pm SD & $66.2 \pm 11.6$ & $65.3 \pm 12.2$ & $66.9 \pm 10.9$ & .009 \\
\hline Female sex, n (\%) & $510(30.1)$ & $242(36.6)$ & $268(35.7)$ & .72 \\
\hline Caucasian race, $\mathrm{n}(\%)$ & $927(65.8)$ & $422(63.8)$ & $505(67.2)$ & .078 \\
\hline African American race, $\mathrm{n}(\%)$ & $406(28.8)$ & $197(29.8)$ & $209(27.8)$ & \\
\hline \multicolumn{5}{|l|}{ Risk factors } \\
\hline $\mathrm{BMI}, \mathrm{kg} / \mathrm{m}^{2}$, mean $\pm \mathrm{SD}$ & $28.5 \pm 7.8$ & $28.2 \pm 5.4$ & $28.7 \pm 9.4$ & .17 \\
\hline Diabetes, $\mathrm{n}(\%)$ & $593(42)$ & $267(40.4)$ & $326(43.4)$ & .25 \\
\hline Previous MI, n (\%) & $453(32.1)$ & $205(31)$ & $248(33)$ & .42 \\
\hline CHF current, $\mathrm{n}(\%)$ & $330(23.4)$ & $129(21.7)$ & $201(26.7)$ & .001 \\
\hline LVEF, $\%$, mean \pm SD & $49.9 \pm 14.1$ & $50.8 \pm 13.5$ & $49.2 \pm 14.5$ & .03 \\
\hline Dialysis, n (\%) & $56(4)$ & $19(2.9)$ & $37(4.9)$ & .049 \\
\hline $\mathrm{GFR}, \mathrm{mL} / \mathrm{min} / 1.73 \mathrm{~m}^{2}$, mean $\pm \mathrm{SD}$ & $73.9 \pm 52.7$ & $74.7 \pm 47.3$ & $73.3 \pm 57.1$ & .60 \\
\hline $\mathrm{PAD}, \mathrm{n}(\%)$ & $199(14.1)$ & $89(13.5)$ & $110(14.6)$ & .52 \\
\hline Previous CVA, n (\%) & $383(27.2)$ & $153(23.2)$ & $230(30.6)$ & .002 \\
\hline \multicolumn{5}{|l|}{ Type of surgical intervention, $\mathrm{n}(\%)$} \\
\hline Urgent priority & $1036(73.4)$ & $462(69.9)$ & $574(76.4)$ & .006 \\
\hline CABG isolated & $906(64)$ & $441(66.7)$ & 465 (61.9) & .061 \\
\hline CABG valve & $240(17)$ & $95(14.3)$ & 145 (19.3) & .014 \\
\hline Valve isolated & $266(18.8)$ & 125 (18.9) & $141(18.7)$ & .95 \\
\hline \multicolumn{5}{|l|}{ STS risk, $\%$, median (IQR) } \\
\hline STS risk of mortality & $1.4(0.7-3)$ & $1.4(0.7-3)$ & $1.4(0.7-3)$ & $<.001$ \\
\hline STS risk of PPLS & $5.3(2.7-10.7)$ & $4.8(2.4-9.3)$ & $5.9(3.1-11.8)$ & $<.001$ \\
\hline STS risk of prolonged ventilation & $8.4(5.2-14.9)$ & $7.5(4.7-12.9)$ & $9.2(5.5-17.2)$ & $<.001$ \\
\hline \multicolumn{5}{|l|}{ COPD risk factors } \\
\hline Dyspnea at rest, n (\%) & & & $444(59.1)$ & \\
\hline Dyspnea on exertion, n (\%) & & & $639(85.1)$ & \\
\hline Smoker, n $(\%)$ & & & 357 (47.7) & \\
\hline Pack-years (in smokers), median (IQR) & & & $22(4-40)$ & \\
\hline Time from PFTs to surgery, days, mean \pm SD & & & $4.3 \pm 7.4$ & \\
\hline
\end{tabular}

PFT, Pulmonary function test; $S D$, standard deviation; $B M I$, body mass index; $M I$, myocardial infarction; $C H F$ current, congestive heart failure exacerbation within 2 weeks before surgery; $L V E F$, left ventricular ejection fraction; $G F R$, glomerular filtration rate; $P A D$, peripheral arterial disease; $C V A$, cerebrovascular accident; $C A B G$, coronary artery bypass grafting; $C A B G$ valve, coronary artery bypass grafting with valve repair, STS, Society of Thoracic Surgeons; IQR, interquartile range; PPLS, postoperative prolonged length of stay; $C O P D$, chronic obstructive pulmonary disease.

\section{DISCUSSION}

In this study, we found that in routine practice, PFTs are generally performed in patients with a higher burden of comorbidity, scheduled for more complex CT surgery. Calculating STS score based on clinical definitions of lung disease afforded modest discriminatory ability for 3 important postoperative complications. Adding either individual PFT parameters or any of the COPD classifications did not improve the discriminatory ability of STS score alone.

The STS risk model was developed based on the STS national adult cardiac surgery database, comprising nearly
1 million patients. The most recent model, published in 2009, was developed and validated for isolated coronary artery bypass grafting (CABG), isolated valve surgery, and some commonly performed combined valve and CABG surgeries. ${ }^{14-17}$ Based on the definitions used by STS, CLD and its severity can be classified by either specific FEV1 values or by clinical history and medication use when FEV1 data are not available. Ad et $\mathrm{al}^{18}$ compared the classification of patients' lung disease based on clinical history alone and on subsequent spirometry results, and found that using clinical history

TABLE 3. ROC analysis: PFT parameters (AUC) in patients with PFTs

\begin{tabular}{lllcrccc}
\hline \multicolumn{1}{c}{ Outcome } & \multicolumn{1}{c}{ STS } & STS and FEV1 & $\boldsymbol{P}$ value & STS and FVC & $\boldsymbol{P}$ value & STS and FEV1/FVC & $\boldsymbol{P}$ value \\
\hline $\mathrm{RF}^{*}$ & $0.65(0.56-0.74)^{*}$ & $0.69(0.6-0.78)$ & .29 & $0.67(0.58-0.76)$ & .59 & $0.65(0.56-0.74)$ \\
$\mathrm{PPLS} \dagger$ & $0.67(0.6-0.74) \dagger$ & $0.72(0.65-0.79)$ & .08 & $0.7(0.63-0.76)$ & .25 & $0.67(0.6-0.74)$ \\
$30-\mathrm{d}$ mortality $\ddagger$ & $0.74(0.61-0.87) \ddagger$ & $0.79(0.69-0.89)$ & .30 & $0.81(0.71-0.91)$ & .26 & $0.75(0.61-0.88)$ & .99 \\
\hline
\end{tabular}

Compared with the corresponding STS risk in ROC analysis. STS, Society of Thoracic Surgeons; FEVI, forced expiratory volume in 1 second; $F V C$, forced vital capacity; $R F$, respiratory failure; PPLS, prolonged postoperative length of stay. *STS risk of prolonged ventilation. †STS risk of PPLS. $\ddagger$ STS risk of mortality. 
TABLE 4. ROC analysis: COPD classification (AUC) in patients with PFTs

\begin{tabular}{lccccccc}
\hline \multicolumn{1}{c}{ Outcome } & STS & STS and COPD GOLD & $\boldsymbol{P}$ value & STS and COPD ATS & $\boldsymbol{P}$ value & STS and COPD NYS & $P$ value \\
\hline $\mathrm{RF}^{*}$ & $0.65(0.56-0.74)^{*}$ & $0.66(0.57-0.75)$ & .51 & $0.66(0.57-0.75)$ & .50 & $0.65(0.56-0.74)$ \\
$\mathrm{PPLS} \dagger$ & $0.67(0.6-0.74) \dagger$ & $0.71(0.64-0.77)$ & .06 & $0.71(0.64-0.77)$ & .05 & $0.67(0.6-0.74)$ \\
$30-\mathrm{d}$ mortality $\ddagger$ & $0.74(0.61-0.87) \ddagger$ & $0.74(0.58-0.89)$ & .89 & $0.73(0.57-0.88)$ & .77 & $0.72(0.57-0.87)$ & .37 \\
\hline
\end{tabular}

Compared with the corresponding STS risk in ROC analysis. STS, Society of Thoracic Surgeons; COPD, chronic obstructive pulmonary disease; GOLD, Global Strategy for the Diagnosis, Management, and Prevention of COPD; ATS, American Thoracic Society 2001 classification; COPD NYS, New York State criteria for chronic obstructive pulmonary disease (New York State Department of Health Division of Quality and Patient Safety Cardiac Services program using Department of Health Form 2254a 2011); RF, respiratory failure; PPLS, prolonged postoperative length of stay. *STS risk of prolonged ventilation. $\dagger$ STS risk of PPLS. $\ddagger$ STS risk of mortality.

alone to define and stage CLD led to underreporting of chronic lung disease by $39 \%$ and underestimation of the risk for adverse outcomes by up to $25 \%$ compared with the information provided by PFTs. Our results suggest that although both FEV1 and FVC are well-recognized predictors of adverse outcomes after CT surgery, their addition to the current STS definition of CLD based on clinical history and medication use offers little advantage over the STS risk model alone in predicting RF, PPLS, and 30-day mortality. This also holds true for the various
COPD classifications, which are based on PFT parameters. A possible physiological explanation for these findings may be that the examined PFT variables do not depend solely on pulmonary parameters such as airway diameter, degree of obstruction, and lung elasticity but rather on a patient's effort and muscle "strength," characteristics that are already well captured and accounted for in the current STS model. Alternatively, because the STS score provides only modest discrimination for adverse events, we can assume that other unmeasured characteristics, not related
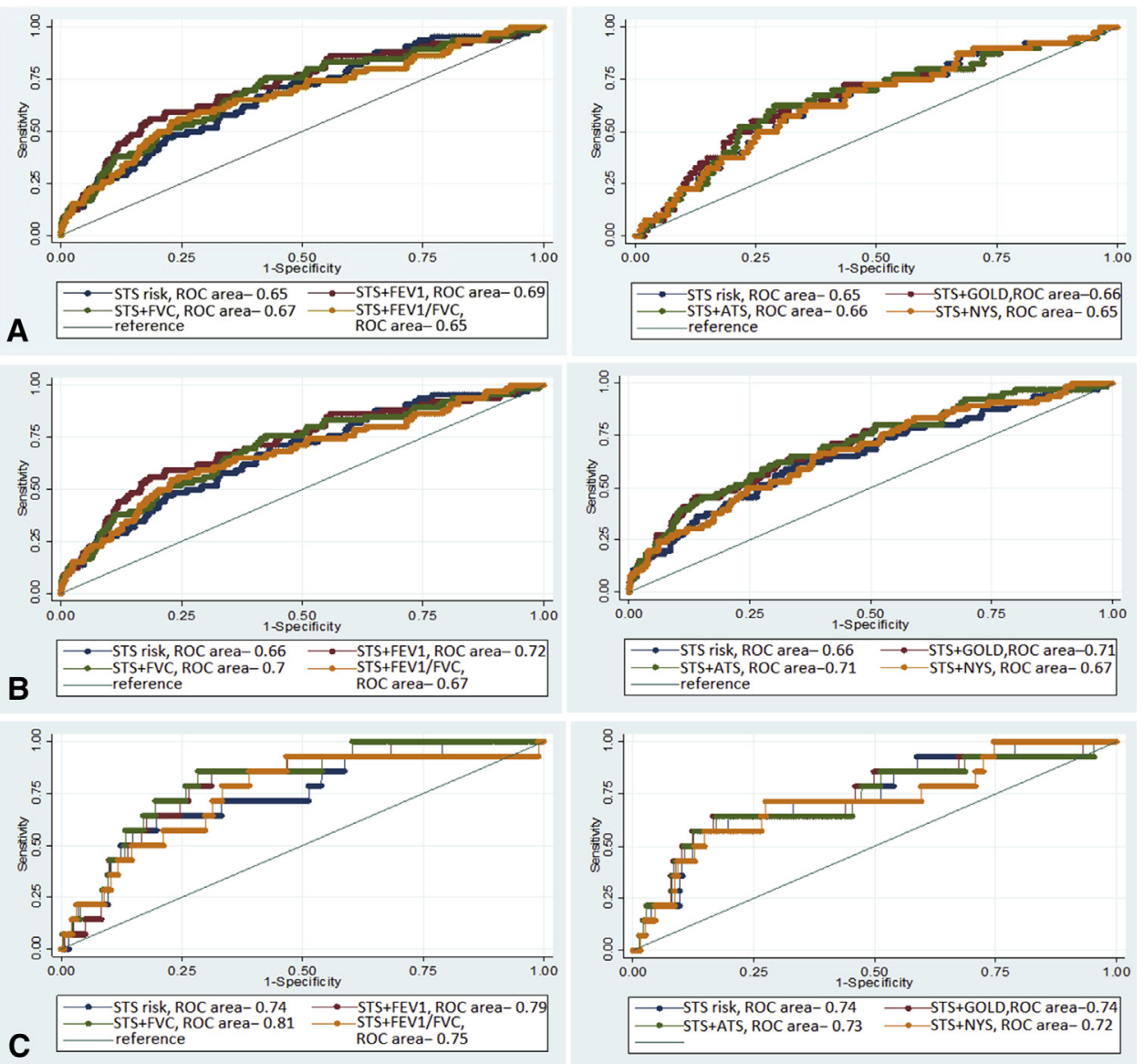

FIGURE 2. Receiver operating characteristic $(R O C)$ analysis in patients with PFT. Panels on the left represent ROC comparison between STS and different components of PFT. Panel son the right represent ROC comparison between STS and different COPD classifications . A, ROC analysis for respiratory. $\mathrm{B}, \mathrm{ROC}$ analysis for prolonged postoperative length of stay. C, ROC analysis for 30-day mortality. FEV1, Forced expiratory volume in 1 second (liters); $F V C$, forced vital capacity (liters); ATS, American Thoracic Society; COPD, chronic obstructive pulmonary disease; GOLD, Global initiative for Chronic Obstructive Lung Disease; NYS, New York State Department of Health. 
to lung pathology, contribute significantly more to outcomes. Furthermore, the presence and severity of chronic lung disease are only 2 of many components of the STS score, and it is unlikely that even perfect classification of this component will alter dramatically the score's performance.

Recently, Shih et $\mathrm{al}^{21}$ analyzed potential associations between variables introduced (ie, PFTs) in STS risk model 2.73 and mortality. They performed multivariable analysis controlling for STS risk of mortality using the 2008 model update, and found a strong association between FEV1 and mortality. Their analysis identified clinical parameters as independent predictors of postoperative mortality. There are some important differences between the study of Shih et al and our present study, however. First, we used STS 2.73 with several new variables and different coefficients for some of the variables compared with the 2008 update. Second, we opted to use clinical parameters, not the 2008 definition, to define CLD for risk calculations. Finally, we aimed to answer a different clinical question, investigating whether adding the results of spirometry tests to the clinical definition of CLD improves discriminatory power.

We recognize some important limitations of our analysis and findings. First, we calculated STS score based solely on clinical data, and did not revise it based on PFT results. Second, there is a potential referral bias of patients excluded from surgery based on the PFT results; however, this occurred in $<1 \%$ of our cohort. There is also a referral bias, in that patients undergoing PFT analysis on clinical grounds might be an older population, and PFTs perhaps might portend better prognostic value in a younger, lower-risk population. Third, during the relatively long time period covered by this study, improvements in technique and perioperative care might have affected the outcomes of interest. Fourth, the STS estimation for risk of RF was designed to predict the risk of mechanical ventilation for $>24$ hours, whereas in our study $\mathrm{RF}$ was defined as intubation for $>72$ hours, as used by NYSDOH. Fifth, PFTs were performed at the discretion of physicians who were not blinded to the results and might have modified treatment strategies accordingly. Sixth, we used STS version 2.73, the most current version at the time of our analysis, for our calculations; however, version 2.81 , with updated coefficients and some changes in the definitions, became publicly available in 2014. Seventh, PFT's were performed at the bedside and not in a formal laboratory; however, based on revious studies finding similar agreement between bedside and laboratory PFT measurements, current guidelines do not recommend laboratory over handheld PFT assessment for the diagnosis of COPD. ${ }^{19,22,23}$ Finally, the study's single-center design might limit external validity.

\section{CONCLUSIONS}

We conclude that STS score calculated with clinical information on lung disease status offers modest discriminatory ability for RF, PPLS, and 30-day mortality after CT surgery, which cannot be improved by adding PFT parameters or PFT-derived COPD categorization. Therefore, routine preoperative PFTs may have only limited clinical utility in patients undergoing CT surgery when the STS score is readily available. Further prospective studies will be helpful in confirming these conclusions.

\section{Conflict of Interest Statement}

Authors have nothing to disclose with regard to commercial support.

\section{References}

1. Saleh HZ, Mohan K, Shaw M, Al-Rawi O, Elsayed H, Walshaw M, et al. Impact of chronic obstructive pulmonary disease severity on surgical outcomes in patients undergoing non-emergent coronary artery bypass grafting. Eur $J$ Cardiothorac Surg. 2012;42:108-13.

2. Filsoufi F, Rahmanian PB, Castillo JG, Chikwe J, Adams DH. Predictors and early and late outcomes of respiratory failure in contemporary cardiac surgery. Chest. 2008;133:713-21.

3. Branca P, McGaw P, Light R. Factors associated with prolonged mechanical ventilation following coronary artery bypass surgery. Chest. 2001; 119:537-46.

4. Reddy SL, Grayson AD, Griffiths EM, Pullan DM, Rashid A. Logistic risk model for prolonged ventilation after adult cardiac surgery. Ann Thorac Surg. 2007;84: 528-36.

5. Trouillet JL, Combes A, Vaissier E, Luyt CE, Ouattara A, Pavie A, et al. Prolonged mechanical ventilation after cardiac surgery: outcome and predictors. J Thorac Cardiovasc Surg. 2009;138:948-53.

6. Kollef MH, Wragge T, Pasque C. Determinants of mortality and multiorgan dysfunction in cardiac surgery patients requiring prolonged mechanical ventilation. Chest. 1995; 107:1395-401.

7. Légaré JF, Hirsch GM, Buth KJ, MacDougall C, Sullivan JA. Preoperative prediction of prolonged mechanical ventilation following coronary artery bypass grafting. Eur J Cardiothorac Surg. 2001;20:930-6.

8. Angouras DC, Anagnostopoulos CE, Chamogeorgakis TP, Rokkas CK, Swistel DG, Connery CP, et al. Postoperative and long-term outcome of patients with chronic obstructive pulmonary disease undergoing coronary artery bypass grafting. Ann Thorac Surg. 2010;89:1112-8.

9. McAllister DA, Wild SH, MacLay JD, Robson A, Newby DE, MacNee W, et al. Forced expiratory volume in one second predicts length of stay and in-hospital mortality in patients undergoing cardiac surgery: a retrospective cohort study. PLoS One. 2013;8:e64565.

10. Cohen AJ, Katz MG, Frenkel G, Medalion B, Geva D, Schachner A. Morbid results of prolonged intubation after coronary artery bypass surgery. Chest. 2000;118:1724-31.

11. Manganas H, Lacasse Y, Bourgeois S, Perron J, Dagenais F, Maltais F, Postoperative outcome after coronary artery bypass grafting in chronic obstructive pulmonary disease. Can Respir J. 2007;14:19-24.

12. Saleh HZ, Shaw M, Al-Rawi O, Yates J, Pullan DM, Chalmers JA, et al. Outcomes and predictors of prolonged ventilation in patients undergoing elective coronary surgery. Interact Cardiovasc Thorac Surg. 2012;15:51-6.

13. Burney PG, Hooper R. Forced vital capacity, airway obstruction and survival in a general population sample from the USA. Thorax. 2011;66:49-54.

14. O'Brien SM, Shahian DM, Filardo G, Ferraris VA, Haan CK, Rich JB, et al. The Society of Thoracic Surgeons 2008 cardiac surgery risk models, part 2: isolated valve surgery. Ann Thorac Surg. 2009;88(1 Suppl):S23-42.

15. Shahian DM, Edwards FH. The Society of Thoracic Surgeons 2008 cardiac surgery risk models: introduction. Ann Thorac Surg. 2009;88(1Suppl):S1.

16. Shahian DM, O'Brien SM, Filardo G, Ferraris VA, Haan CK, Rich JB, et al. The Society of Thoracic Surgeons 2008 cardiac surgery risk models, part 3: valve plus coronary artery bypass grafting surgery. Ann Thorac Surg. 2009;88(1Suppl): S43-62. 
17. Shahian DM, O'Brien SM, Filardo G, Ferraris VA, Haan CK, Rich JB, et al. The Society of Thoracic Surgeons 2008 cardiac surgery risk models, part 1: coronary artery bypass grafting surgery. Ann Thorac Surg. 2009;88:S2-22.

18. Ad N, Henry L, Halpin L, Hunt S, Barnett S, Crippen P, et al. The use of spirometry testing prior to cardiac surgery may impact the Society of Thoracic Surgeons risk prediction score: a prospective study in a cohort of patients at high risk for chronic lung disease. J Thorac Cardiovasc Surg. 2010;139:686-91.

19. Vestbo J, Hurd SS, Agusti AG, Jones PW, Vogelmeier C, Anzueto A, et al. Global strategy for the diagnosis, management, and prevention of chronic obstructive pulmonary disease: GOLD executive summary. Am J Respir Crit Care Med. 2013; 187:347-65

20. Celli BR, MacNee W, ATS/ERS Task Force. Standards for the diagnosis and treatment of patients with COPD: a summary of the ATS/ERS position paper. Eur Respir J. 2004;23:932-46.
21. Shih T, Paone G, Theurer PF, McDonald D, Shahian DM, Prager RL. The Society of Thoracic Surgeons Adult Cardiac Surgery Database version 2.73: more is better. The Ann Thorac Surg. 2015;100:516-21.

22. Barr RG, Stemple KJ, Mesia-Vela S, Basner RC, Derk SJ, Henneberger PK, et al Reproducibility and validity of a handheld spirometer. Respir Care. 2008;53: 433-41.

23. Brusasco V, Crapo R, Viegi G, American Thoracic Society; European Respiratory Society. Coming together: the ATS/ERS consensus on clinical pulmonary function testing. Eur Respir J. 2005;26:1-2.

Key Words: STS risk, pulmonary failure, pulmonary function test

\title{
EDITORIAL COMMENTARY
}

\section{What's in a word?: The importance of data to support a precise definition}

\author{
Juan A. Crestanello, MD
}

\author{
From the Division of Cardiac Surgery, Wexner Medical Center, The Ohio State University, Columbus, Ohio. \\ Disclosures: Author has nothing to disclose with regard to commercial support. \\ Received for publication Nov 10, 2015; accepted for publication Nov 12, 2015; available ahead of print Dec 11, \\ 2015. \\ Address for reprints: Juan A. Crestanello, MD, Division of Cardiac Surgery, Wexner Medical Center, The Ohio \\ State University, N-820 Doan Hall, 410 W 10th Ave, Columbus, OH 43210 (E-mail: juan.crestanello@osumc. \\ edu). \\ J Thorac Cardiovasc Surg 2016;151:1189-90 \\ $0022-5223 / \$ 36.00$ \\ Copyright (c) 2016 by The American Association for Thoracic Surgery \\ http://dx.doi.org/10.1016/j.jtcvs.2015.11.021
}

Understanding how risk factors are defined is of paramount importance. Risk assessment based on incorrect understanding of the definition of a risk factor may lead to inappropriate decisions and have a substantial effect on outcomes. An example is the definition of chronic lung disease (CLD), in the Society of Thoracic Surgeons (STS) database. ${ }^{1}$ CLD is defined by the presence of airway obstruction, hypoxemia, hypercarbia, and by the use of inhaled or oral bronchodilators or steroid therapy. Severity of CLD is defined by various degrees of these impairments. Without precise spirometry and arterial blood gas data to support the correct classification, more than one third of patients receive incorrect assignments to a CLD severity category, resulting in over- or under-estimation of their surgical risk. ${ }^{2}$

The STS adult cardiac surgery database provides clinicians and patients with risk models that adjust patient outcomes for procedure and preoperative risk factors. ${ }^{3-5}$ Chronic lung disease is one of the risk factors included in the STS model for mortality, renal failure, prolonged

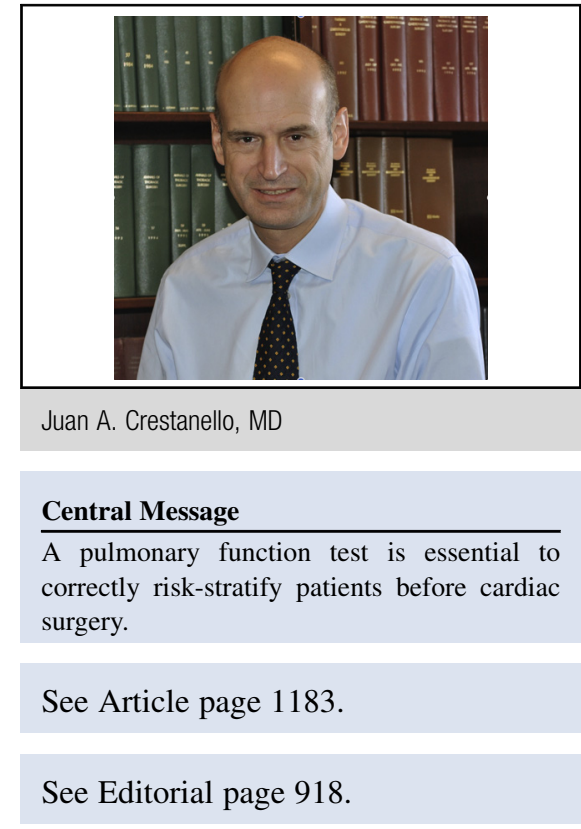

ventilation, sternal wound infection, reoperation, and length of hospital stay. ${ }^{3-5}$ Mild, moderate, and severe CLD increases the odds ratio for those complications. A total of $20 \%$ of the almost 1 million patients used in developing the current STS risk model had CLD.

Given that a pulmonary function test (PFT) has not been a routine part of the preoperative evaluation before cardiac surgery, most patients are assigned a CLD category using only 


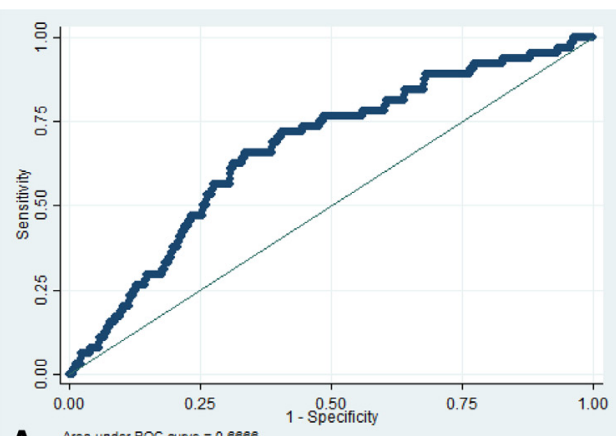

A Ares under ROC curve $=0.888$

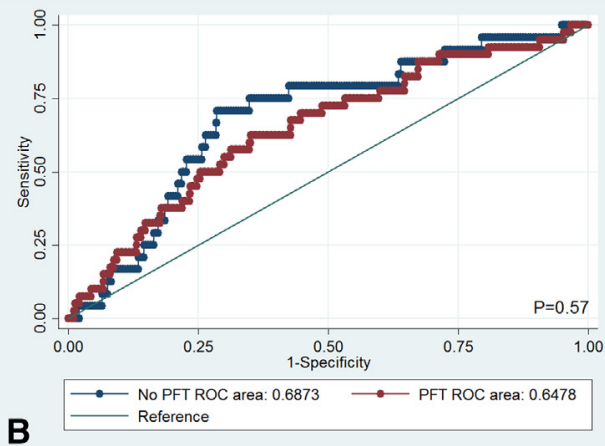

B

FIGURE E1. A, Receiver operating characteristic $(R O C)$ analysis for respiratory failure $(R F)$ in all patients. B, ROC analysis for RF in patients with and without pulmonary function tests (PFTs).

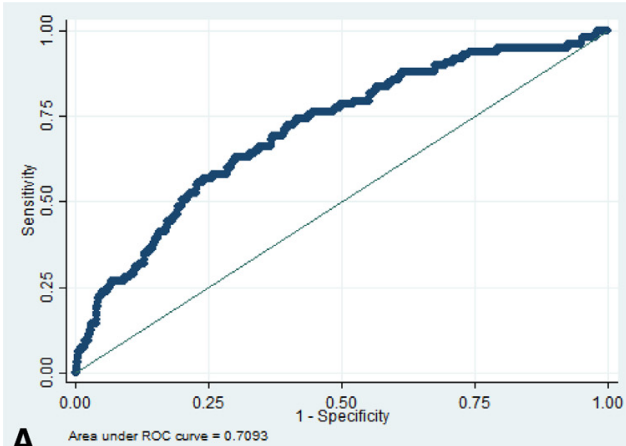

A
Area under ROC curve $=0.7093$

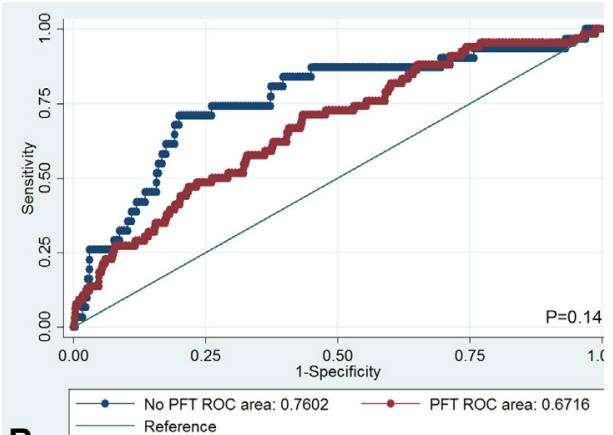

B

FIGURE E2. A, Receiver operating characteristic $(R O C)$ analysis for prolonged postoperative length of stay $(P P L S)$ in all patients. B, ROC analysis for PPLS in patients with and without pulmonary function tests (PFTs).
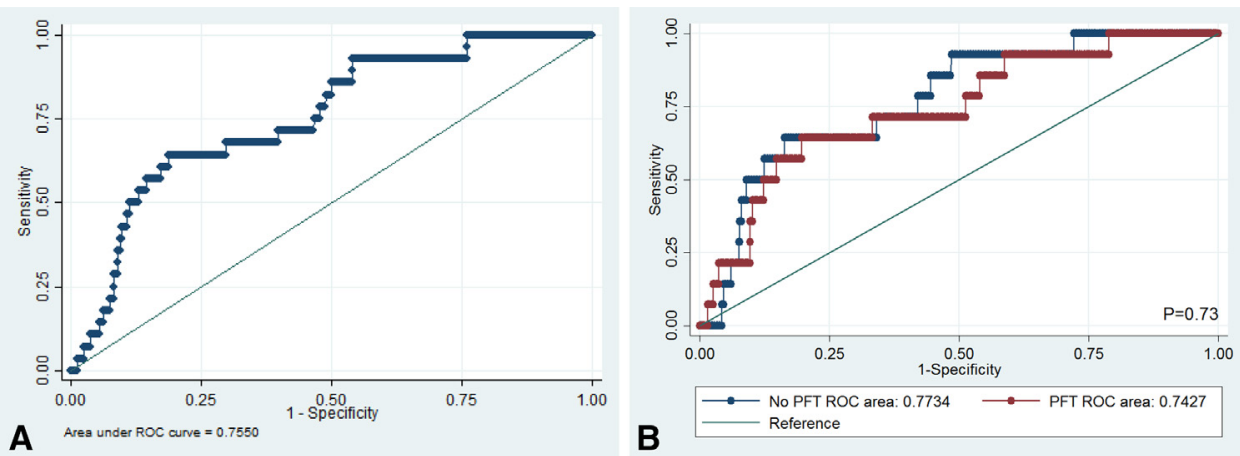

FIGURE E3. A, Receiver operating characteristic $(R O C)$ analysis for 30-day mortality in all patients. B, ROC analysis for 30-day mortality in with and without pulmonary function tests $(P F T s)$. 

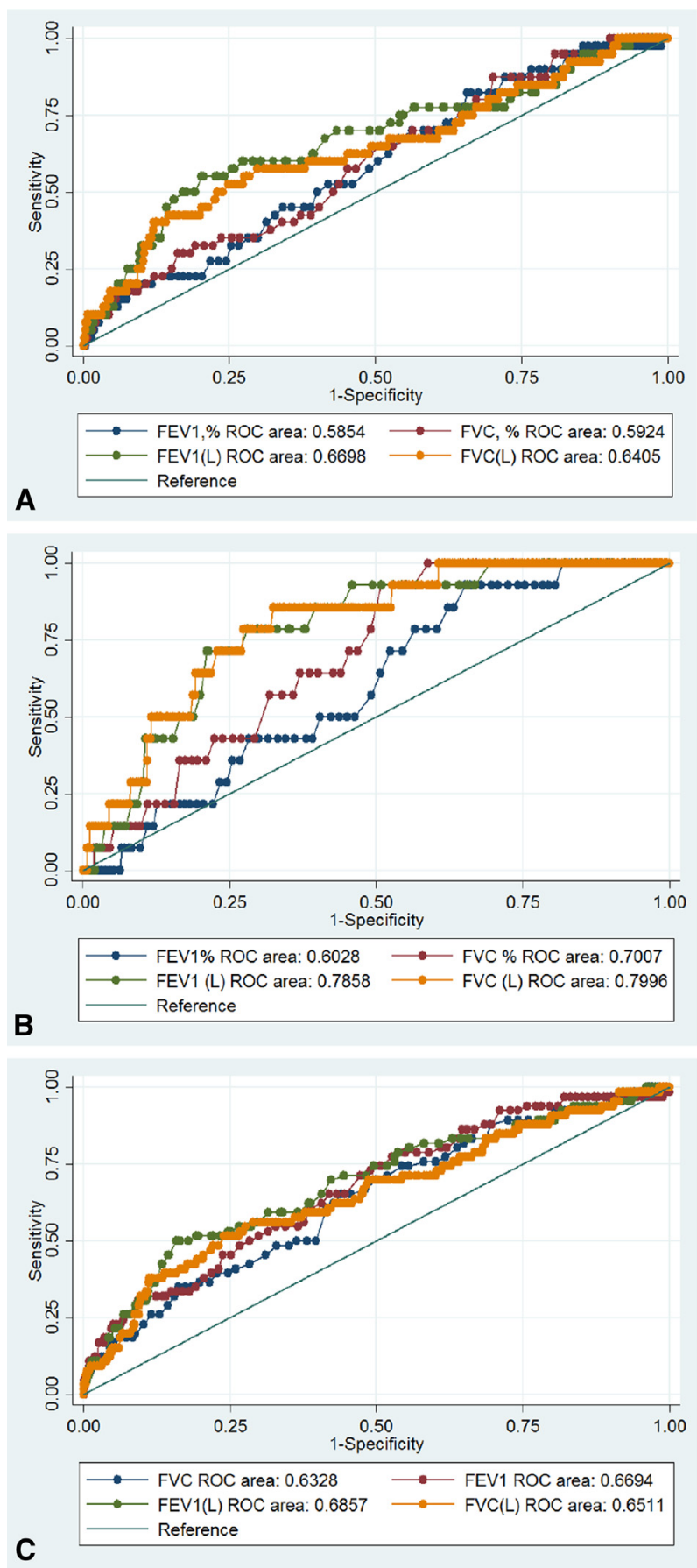

FIGURE E4. Receiver operating characteristic (ROC) analyses comparing normalized and nonnormalized forced expiratory volume in 1 second $(F E V 1)$ and forced vital capacity $(F V C)$ values. A, ROC analysis for respiratory failure $(R F)$. B, ROC analysis for mortality. C, ROC analysis for prolonged postoperative length of stay $(P P L S)$.
TABLE E1. Results of the multivariate logistic regression analysis for studied outcomes

\begin{tabular}{|c|c|c|c|}
\hline Variable & Odds ratio & 95 $\%$ Confidence interval & $P$ value \\
\hline \multicolumn{4}{|c|}{ RESP_FAIL: logistic regression } \\
\hline MAL_VENT & 11.6 & $0.522-118$ & .0496 \\
\hline REN_DIAL & 0.0848 & $0.00269-1.35$ & .0991 \\
\hline CREATININE & 1.24 & $0.912-1.56$ & .103 \\
\hline iValve & 1.74 & $0.879-3.37$ & .106 \\
\hline age & 1.03 & $0.993-1.06$ & .131 \\
\hline SEX2 & 0.534 & $0.221-1.28$ & .16 \\
\hline HEIGHT & 0.972 & $0.929-1.02$ & .204 \\
\hline FEV1liter & 0.455 & $0.245-0.83$ & .0114 \\
\hline MAL_VENT & 10.8 & $0.485-107$ & .0562 \\
\hline REN_DIAL & 0.0894 & $0.00287-1.39$ & .104 \\
\hline CREATININE & 1.23 & $0.913-1.55$ & .104 \\
\hline iValve & 1.8 & $0.913-3.5$ & .0834 \\
\hline age & 1.03 & $0.998-1.07$ & .0779 \\
\hline SEX2 & 0.557 & $0.229-1.36$ & .196 \\
\hline HEIGHT & 0.972 & $0.929-1.02$ & .221 \\
\hline FVCliters & 0.624 & $0.38-0.95$ & .0286 \\
\hline \multicolumn{4}{|c|}{ THIRTYDAY: logistic regression } \\
\hline REN_DIAL & 4.29 & $0.855-16.8$ & .0481 \\
\hline age & 1.05 & $0.997-1.11$ & .0789 \\
\hline SEX2 & 0.493 & $0.12-2.08$ & .326 \\
\hline HEIGHT & 0.979 & $0.907-1.06$ & .581 \\
\hline FVCliters & 0.273 & $0.108-0.659$ & .00476 \\
\hline REN_DIAL & 4.9 & $1-18.7$ & .0279 \\
\hline age & 1.05 & $0.996-1.11$ & .0837 \\
\hline SEX2 & 0.56 & $0.138-2.35$ & .419 \\
\hline HEIGHT & 0.971 & $0.9-1.04$ & .431 \\
\hline FEV1liter & 0.235 & $0.0718-0.704$ & .0124 \\
\hline \multicolumn{4}{|c|}{ POS $>14$ days: logistic regressions } \\
\hline MAL_VENT & 5.46 & $0.245-49.889$ & .1698 \\
\hline Diabetes & 1.24 & $0.747-2.034$ & .4067 \\
\hline EJEC_FRA & 0.98 & $0.967-0.998$ & .0274 \\
\hline icabg & 0.57 & $0.335-0.946$ & .0315 \\
\hline FEV1liter & 0.38 & $0.230-0.616$ & .0001 \\
\hline COPD & 1.19 & $0.642-2.128$ & .5708 \\
\hline age & 0.99 & $0.969-1.015$ & .4749 \\
\hline SEX2 & 0.84 & $0.425-1.672$ & .6264 \\
\hline HEIGHT & 1.01 & $0.977-1.046$ & .5384 \\
\hline MAL_VENT & 4.88 & $0.222-43.478$ & .196 \\
\hline Diabetes & 1.19 & $0.722-1.964$ & .486 \\
\hline EJEC_FRA & 0.98 & 0.966-0.997 & .021 \\
\hline icabg & 0.56 & $0.330-0.929$ & .026 \\
\hline COPD & 1.86 & $1.032-3.250$ & .033 \\
\hline age & 0.99 & $0.972-1.017$ & .597 \\
\hline SEX2 & 0.85 & $0.431-1.686$ & .646 \\
\hline HEIGHT & 1.01 & $0.978-1.048$ & .4907 \\
\hline FVCliters & 0.50 & $0.339-0.722$ & .0003 \\
\hline
\end{tabular}

RESP_FAIL, respiratory failure; $M A L_{-} V E N T$, malignant ventricular arrhythmias; REN_DIAL, renal dialysis; iValve, isolated valve surgery (mitral or aortic); $S E X 2$, female sex; HEIGHT, patient's height (cm); FEVlliter, forced expiratory volume in 1 second, liters; FVCliters, forced vital capacity, liters; THIRTYDAY, patient vital status at day 30 following CT surgery (dead/alive); Diabetes, type 2 diabetes mellitus; EJEC_FRA, left ventricular ejection fraction; icabg, isolated coronary artery bypass grafting; COPD, chronic obstructive pulmonary disease (FEV1/FVC $<0.7$ ). 
TABLE E2. Observed/expected ratio

\begin{tabular}{lccc}
\hline \multicolumn{1}{c}{ Outcome } & All patients & No PFTs & PFTs \\
\hline RF* $^{*}$ & 1.45 & 3 & 1.08 \\
PPLS $\dagger$ & 1.9 & 1.7 & 1.94 \\
$30-\mathrm{d}$ mortality $\ddagger$ & 4 & 4.67 & 2.8 \\
\hline Here $10 \%$ predicted probability was used to define expected RF or expected & $30-$ day \\
mortality, and $20 \%$ predicted probability was used to define expected PPLS. PFT, \\
Pulmonary function test; $R F$, respiratory failure; PPLS, prolonged postoperative \\
length of stay. *For RF, risk of prolonged ventilation was STS risk. †For PPLS, \\
prolonged length of stay was STS risk. †ेFor 30-day mortality, risk of mortality was \\
STS risk.
\end{tabular}

TABLE E3. Observed/expected ratio in patients with PFTs

\begin{tabular}{lccc}
\hline \multicolumn{1}{c}{ Outcome } & RF* & PPLS $\dagger$ & 30-d mortality $\ddagger$ \\
\hline STS risk & 1.08 & 1.94 & 2.8 \\
STS risk + FEV1 & 0.52 & 1.27 & 1.56 \\
STS risk + FVC & 0.66 & 1.43 & 1.27 \\
STS risk + FEV1 + FVC & 0.53 & 1.22 & 1.4 \\
\hline
\end{tabular}

Here $10 \%$ predicted probability was used to define expected RF or expected 30 -day mortality, and $20 \%$ predicted probability was used to define expected PPLS. $R F$, Respiratory failure; $P P L S$, prolonged postoperative length of stay; $S T S$, Society of Thoracic Surgeons; $F E V 1$, forced expiratory volume in 1 second; $F V C$, forced vital capacity. *For RF, risk of prolonged ventilation was STS risk. †For PPLS, prolonged

length of stay was STS risk. ‡For 30-day mortality, risk of mortality was STS risk. 